\title{
Atomic Absorption Spectroscopy
}

National Cancer Institute

\section{Source}

National Cancer Institute. Atomic Absorption Spectroscopy. NCI Thesaurus. Code C85574.

A spectrometric method that determines the type and concentration of metal elements in a sample, based upon the principle that each elemental metal absorbs a particular waveleng th of ultraviolet light when exposed to heat. 